\title{
A case of tubal hydatidiform mole
}

\author{
Ouafae Slimani $^{1 *}$, Fz Fdili Alaoui ${ }^{1}$, Sofia Jayi ${ }^{1}$, Hekmat Chaara ${ }^{1}$, Hakima Bouguern ${ }^{1}$, M. A. Malhouf ${ }^{1}$, \\ Nawal Hamas ${ }^{2}$, Amal Bennani ${ }^{2}$, Afaf Amarti ${ }^{2}$ \\ ${ }^{1}$ Department of Gynecology Obstetric II, Teaching Hospital Hassan II, Fez, Morocco \\ ${ }^{2}$ Department of Anatomopathology, Teaching Hospital Hassan II, Fez, Morocco \\ Email: ${ }^{*}$ sliwaf-80@hotmail.fr
}

Received 24 June 2013; revised 22 July 2013; accepted 30 July 2013

Copyright (c) 2013 Ouafae Slimani et al. This is an open access article distributed under the Creative Commons Attribution License, which permits unrestricted use, distribution, and reproduction in any medium, provided the original work is properly cited.

\begin{abstract}
Tubal hydatidiform mole is an uncommon condition with about 40 confirmed cases in the accessible literature. The patient usually presents with symptoms and signs of a classical ectopic pregnancy, and it is only after histological examination and DNA ploidy analysis of the conceptus that a hydatidiform mole is diagnosed. We present an unusual case of primi gravida at 6 weeks gestation that was diagnosed as having ectopic pregnancy.
\end{abstract}

Keywords: Tubal Ectopic Pregnancy; Molar Pregnancy; Ectopic Pregnancy

\section{INTRODUCTION}

The incidence of ectopic pregnancy is 20 per 1000 pregnancies. Hydatidiform moles occur in 1 per 1000 pregnancies. Thus, the incidence of the two occurring together is very rare [1].

Our case demonstrates an unusual presentation of a hydatidiform mole. It illustrates the importance of histological examination of products of conception following surgical removal of the conceptus in ectopic pregnancies; only then it is possible to reach the correct diagnosis and offer appropriate counselling and follow-up to the patient.

\section{CASE PRESENTATION}

Mme R.S, 40-year-old, multiparous, at 6 weeks's gestation by last menstrual period, presented the gynecological emergency for lower abdominal pain.

On examination, the patient had a blood pressure of 100/70 and a pulse of $100 \mathrm{bpm}$. She was well orientated, afebrile and had a slight pallor. She had some lower abdominal discomfort with more tenderness at the right

*Corresponding author. iliac fossa, but there was no rebound or guarding.

Blood tests were carried out in the form of full blood count, B-human chorionic gonadotropin (B-HCG) and blood grouping. Hb was $8.0 \mathrm{~g} / \mathrm{l}$, B-HCG was $7981 \mathrm{U} / \mathrm{l}$ and grouping was $\mathrm{O}+$, Pelvic ultrasonography was performed with an irregular echogenic mass in the right adnexa $(5 \mathrm{~cm} \times 4 \mathrm{~cm})$, with peritoneal effusion.

Given the unavailability of emergency laparoscopy, the patient underwent a laparotomy objectifying tubal ectopic pregnancy $(4 \mathrm{~cm} \times 4 \mathrm{~cm})$ broken with intraperitoneal effusion of average abundance which was sucked. Right salpingectomy was performed and Histology (Figures 1 and 2) was in favor of a partial mole tubal

The patient made an uneventful recovery and was discharged home 3 days after the procedure. She was followed with weekly quantitative B-HCG titers until three successive B-HCG levels were negative. She was advised to avoid pregnancy for 12 months and was started on oral contraceptive pills.

\section{DISCUSSION}

The incidence of ectopic pregnancy is 20 per 1000 pregnancies. Hydatidiform moles occur in 1 per 1000 pregnancies [1]. Thus, the incidence of the two occurring together is very rare. Only 42 cases have been reported in the medical literature, and in many of these, accurate diagnosis is uncertain.

Gestational trophoblastic disease can be preceded by any type of pregnancy, including a term pregnancy, abortion, molar gestation, or rarely by tubal gestation.

Hydatidiform moles arise due to abnormal fertilization. In a complete mole, the chromosomal complement is 46, $\mathrm{XX}$ with the genome paternal in origin. This is usually caused by fertilization of an empty ovum by a haploid spermatozoon, which subsequently duplicates. Occasionally cases occur by fertilization with two sperm [2]. In contrast, partial moles arise from dispermic fertilization of a haploid ovum, resulting in a triploid genome 




Figure 1. Tumor section showing tubal wall (in the upper left), with villus molars at the tubal lumen (down and right) ( $\mathrm{H}$ and $\mathrm{E}$ stain $\times 50)$.



Figure 2. chorionic villus axis in dropsy avascular with trophoblastic proliferation ( $\mathrm{H}$ and $\mathrm{E}$ stain $\times 100$ ).

\section{[3].}

Several studies have attempted to define histopathological criteria for the diagnosis of complete and partial hydatidiform moles. Czernobilsky et al. [4] characterized the former by the presence of universal oedema of chorionic villi (often with cistern formation), mesenchymal (stromal) karyorrhexis, the absence of nucleated fetal erythrocytes, vacuolation of the syncytiotrophoblast and proliferation of cytotrophoblast. In contrast, partial moles were characterized by the presence of intraluminal nucleated fetal erythrocytes, focal hydropic degeneration of villi, scalloping of villi, and moderate hyperplasia of the syncytiotrophoblast with associated vacuolation.

Typically, hydatiform molar pregnancies present in the first trimester with bleeding, uterine size greater than dates, nondetectable fetal heart tones, or hyperemesis. Ultrasound findings of multiple echogenic areas of villi and clots alone with the absence of a fetus are extremely reliable in making the diagnosis of hydatidiform molar pregnancy [5].

It has been previously reported that molar ectopic pregnancy may be indistinguishable from nonmolar tubal pregnancy on the basis of hCG measurements before surgical intervention [6].

The management of ectopic molar pregnancies consists of surgically removing the conceptus with no obvious preference for laparoscopy or laparotomy provided that the whole trophoblast is removed [7].

Histologic discrimination between partial mole, complete mole and hydropic abortion can be a challenge to the pathologist; ploidy evaluation helps in this scenario. In cases of doubt regarding the type of molar pregnancy, DNA flow cytometric analysis helps to determine ploidy. Deoxyribonucleic acid flow cytometry is only of value in distinguishing a diploid from a triploid mole once the diagnosis is made histologically [8]; it does not help to distinguish complete mole from hydropic abortion.

In fact, Conran et al. [9] found that, even when both macroscopic and microscopic features were considered, the interobserver agreement between histopathologists attempting to categorize cases as complete or partial mole was poor. Better agreement could be achieved when DNA flow cytometric analyses were also used. Van de Kaa et al. [10] were able to demonstrate that the majority of complete hydatidiform moles were DNA polyploid and had a high frequency of numerical chromosomal aberrations in the hyperplastic trophoblast. Whilst the majority of partial moles were DNA-triploid and a significant proportion (30\%) were DNA-polyploid. Of the hydropic abortions studied, 60\% showed diploidy, whilst 39\% were triploid. Fukunaga et al. [11] observed that $56 \%$ of complete moles were tetraploid, requiring the same close follow-up given to patients with diploid complete moles. In the same study, all 10 hydropic abortions had a tetraploid chromosome complement. Hemming et al. [12] performed DNA flow cytometry on 88 molar placentas and demonstrated that the majority of complete moles (94\%) were diploid and the majority of partial moles (65\%) were triploid.

The prognosis of ectopic molar pregnancies is the same as for other forms of gestational trophoblastic disease [7].

\section{CONCLUSIONS}

Diagnosis of molar ectopic pregnancy is a rare event. The histological examination of the surgically removed conceptus in ectopic pregnancies is essential for appropriate follow-up to be arranged.

The combination of histological features and DNA flow cytometry is required for the assessment of cases of suspected tubal ectopic hydatidiform mole.

\section{REFERENCES}

[1] Chauhan, S., Diamond, M.P. and Johns, D.A. (2004) A case of molar ectopic pregnancy. Fertility and sterility, 
81, 1140-1141.

[2] Jacobs, P.A., Szulman, A.E., Funkhouser, J., Matsuura, J.S. and Wilson, C.C. (1982) Human triploidy: Relationship between parental origin of the additional haploid complement and development of partial hydatidiform mole. Annals of Human Genetics, 46, 223-231. http://dx.doi.org/10.1111/j.1469-1809.1982.tb00714.x

[3] Depypere, H.T., Dhont, M., Verschraegen-Spae, M.R. and Coppens, M. (1993) Tubal hydatidiform mole. American Journal of Obstetrics \& Gynecology, 169, 209-210. http://dx.doi.org/10.1016/0002-9378(93)90168-I

[4] Czernobilski, B., Barash, A. and Lancet, M. (1982) Partial moles: A clinicopathological study of 25 cases. Obstetrics \& Gynecology, 59, 75-77.

[5] American College of Obstetricians and Gynecologists. (1993) Management of gestational trophoblastic disease. ACOG Technical Bulletin No. 178, Washington DC.

[6] Chase, J.S., Check, J.H., Nowroozi, K. and Wu, C.H. (1987) First-trimester serum levels of the beta-subunit of human chorionic gonadotropin in a tubal molar pregnancy. American Journal of Obstetrics \& Gynecology, 157, 910.

[7] Gillespie, A.M., Lidbury, E.A., Tidy, J.A., et al. (2004) The clinical presentation, treatment, and outcome of patients diagnosed with possible ectopic molar gestation.
International Journal of Gynecological Cancer, 14, 366369.

http://dx.doi.org/10.1111/j.1048-891X.2004.014223.x

[8] Burton, J.L., Lidbury, E.A., Gillespie, A.M., Tidy, J.A., Smith, O., Lawry, J., et al. (2001) Over-diagnosis of hydatidiform mole in early tubal ectopic pregnancy. Histopathology, 38, 409-417. http://dx.doi.org/10.1046/j.1365-2559.2001.01151.x

[9] Conran, R.M., Hitchcock, C.L., Popek, E.J., et al. (1993) Diagnostic considerations in molar gestations. Human Pathology, 24, 41-48.

[10] van de Kaa, C.A., Hanselaar .A.G., Hopman, A.H.N., et al. (1993) DNA cytometric and interphase cytogenetic analyses of paraffinembedded hydatidiform moles and hydropic abortions. The Journal of Pathology, 170, 229238.

[11] Fukunaga, M., Endo, Y. and Ushigome, S. (1996) Clinicopathologic study of tetraploid hydropic villous tissues. Archives of Pathology \& Laboratory Medicine, 120, 569572.

[12] Hemming, J.D., Quirke, P., Womack, C., Wells, M., Elston, C.W. and Bird, C.C. (1987) Diagnosis of molar pregnancy and persistent trophoblastic disease by flow cytometry. Journal of Clinical Pathology, 40, 615-620. 